\title{
Epiglottitis and torsade de pointes tachycardia
}

Carl-Magnus Pripp, Per Blomström

\begin{abstract}
Severe throat infection is not usually associated with a higher risk of paroxysmal attacks of torsade de pointes tachycardia. A patient is reported in whom epiglottitis was associated with the sudden development of cardiac syncope caused by an acquired adrenergicdependent long QT syndrome and the development of ventricular arrhythmias.
\end{abstract}

(Br Heart f 1994;72:205-208)

\section{Case report}

A 70 year old man with a history of essential hypertension was admitted to the emergency ward with fever, dyspnoea, and severe throat pain. He had been treated with propranolol (80 $\mathrm{mg}$ daily), polythiazide (1 $\mathrm{mg}$ daily), and hydralazine ( $50 \mathrm{mg}$ three times a day), during which time his electrocardiogram was normal (fig 1). Epiglottitis was diagnosed. In view of his severe respiratory distress, endotracheal intubation was performed and the patient was treated with mechanical ventilation for 10 days. A parapharyngeal abscess developed on the right side of his neck. Computed tomography localised the abscess, surrounded by a severe inflammatory reaction, near the carotid artery and the sympathetic nerves on this side (fig 2). On the third day the abscess was drained through an incision along the sternocloidomastoid muscle, beneath the omohyoid muscle, and medial to the vessels. A digital dissection towards the abscess was performed. The patient was discharged from hospital after four weeks.

Seven weeks later he was readmitted because of repeated transient sudden attacks of unconsciousness. During these attacks he had no signs of tonic or clonic movements or faecal or urinary incontinence. After each episode he felt exhausted and found it difficult to get up off the floor.

No abnormalities were found on physical examination. Routine laboratory tests were normal with serum digoxin concentration of $1.9 \mathrm{nmol} / \mathrm{l}$. A consultant neurologist found no signs of neurological deficits or neurological disease. Apart from a slightly enlarged heart, the chest $x$ ray showed no other changes. Treatment with digitalis and propranolol was stopped.
Department of Cardiology,

University Hospital of

Lund, S-221 85 Lund

C-M Pripp

P Blomström

Correspondence to:

Dr Carl-Magnus Pripp

Department of Cardiology,

University Hospital of Lund S-221 85 Lund, Sweden.
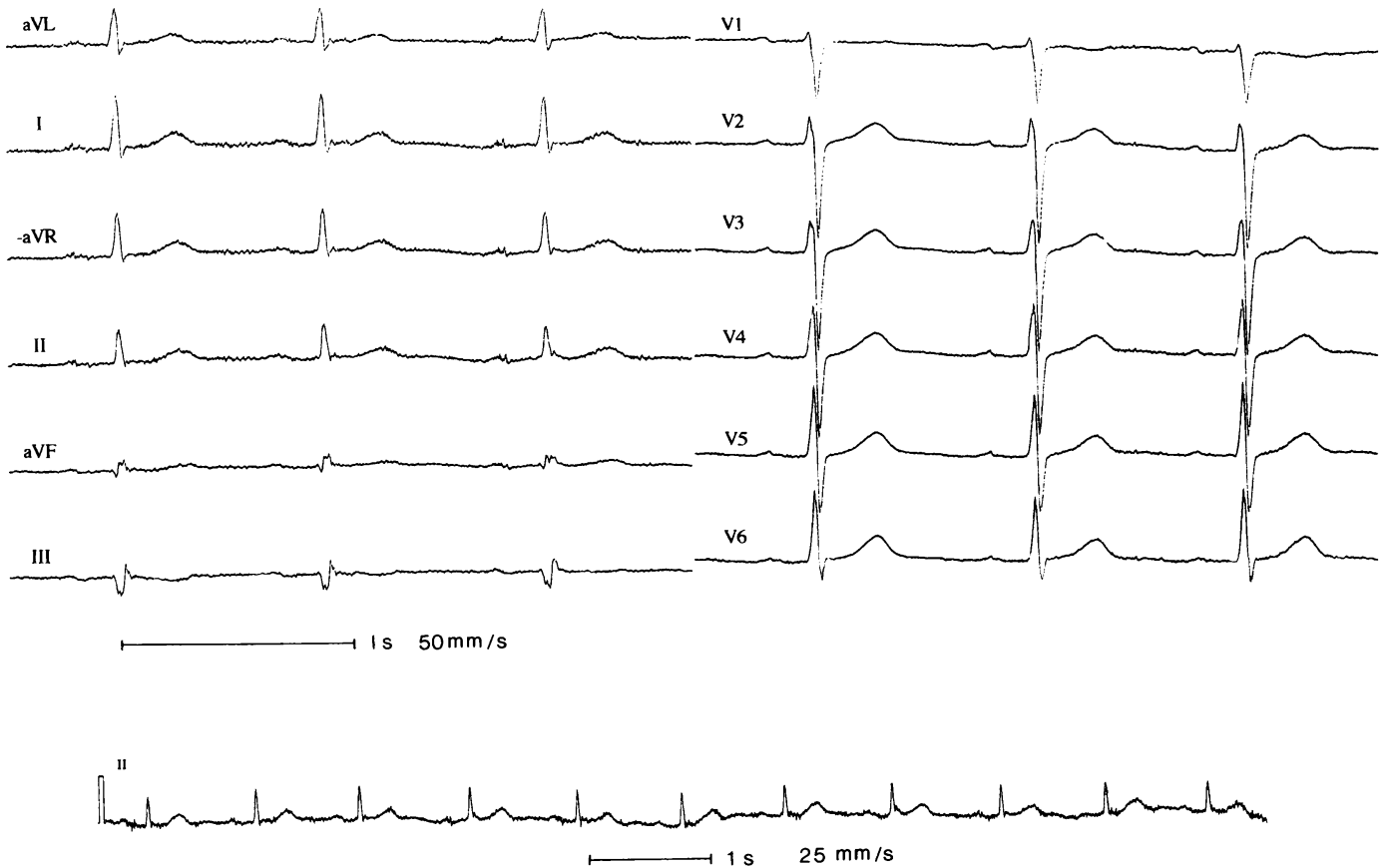

Figure 1 Electrocardiogram recorded before the epiglottitis developed (paper speed $50 \mathrm{~mm} / \mathrm{s}$, rhythm strip $25 \mathrm{~mm} / \mathrm{s}$ ). 


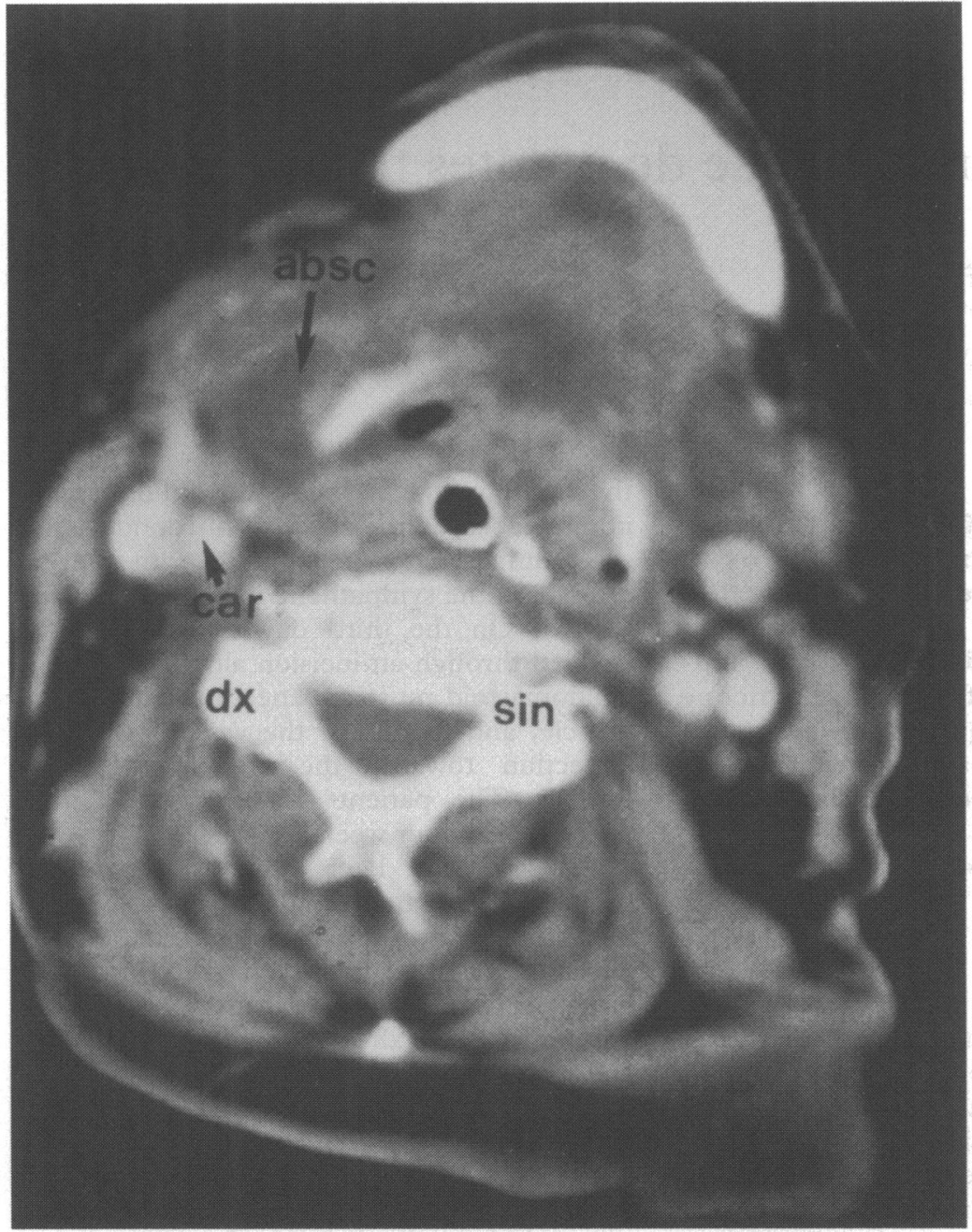

Figure 2 Computed tomogram showing a parapharyngeal abscess (absc, arrow), and the inflammatory reaction surrounding it, affecting the vessels at the right side of the neck (car), absc, abscess; car, carotid artery; dx, right; sin, left.
A resting electrocardiogram showed sinus bradycardia with a ventricular rate of 45 beats per minute, a normal corrected QT interval (QTc), and a prominent $U$ wave (fig 3). Twenty four hour Holter monitoring showed an unusually stable sinus rhythm with a frequency varying between $45-85$ beats per minute and single supraventricular and ventricular extrasystoles. Furthermore, during the daytime there were two episodes of transient ventricular tachycardia (fig 4) when the patient felt dizzy. The ventricular rates during the attacks were 170 beats per minute and 200 per minute, and the attacks lasted seven and nine seconds respectively. The ventricular tachycardias were of the torsade de pointes type and were preceded by an episode of sinus bradycardia and ventricular extra systoles (fig 4). An exercise test, up to $95 \mathrm{~W}$, showed no signs of coronary artery disease; the corrected QT interval was slightly prolonged $(0.47 \mathrm{~s})$ during rest and increased to : maximum of $0.49 \mathrm{~s}$ during work. No arrhyth mias were seen. A cold pressor test showed no QT prolongation compared with the rest ing state. Intravenous injection of a bolus dose of isoprenaline (isoproterenol) $(2 \mu \mathrm{g}$ produced prolongation of QTc from $0.47 \mathrm{~s} \mathrm{t}$, $0.50 \mathrm{~s}$.

We attributed the patient's episodes of unconsciousness to attacks of torsade de pointes tachycardia caused by an acquired adrenergic-dependent long QT syndrome, because there was no family history of syncope, sudden death or long QT syndrome, nor was the patient taking drugs known to cause torsade de pointes tachycardia. Because the attacks of ventricular tachycardia were preceded by episodes of sinus bradycardia
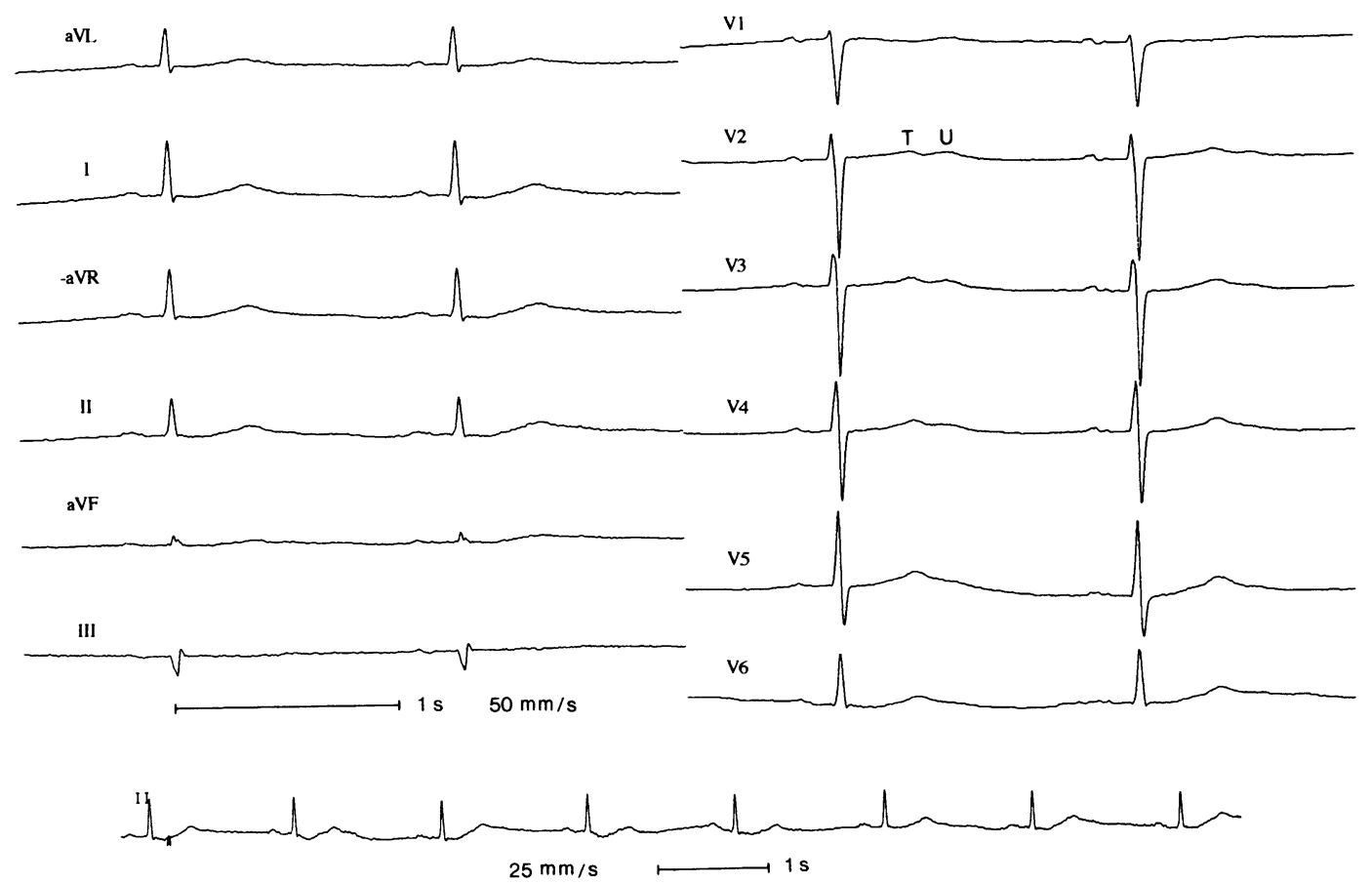

Figure 3 Electrocardiogram recorded after an attack of unconciousness showing a normal corrected QT interval but large $T$ waves $(T)$ and $U$ waves $(U)$ (paper speed $50 \mathrm{~mm} / \mathrm{s}$, rhythm strip $25 \mathrm{~mm} / \mathrm{s}$ ). 
Figure 4 Holter monitoring showing unusually constant $R R$ intervals and episodes of torsade de pointes tachycardia, preceded by an episode of sinus bradycardia with single ventricular extrasystoles.

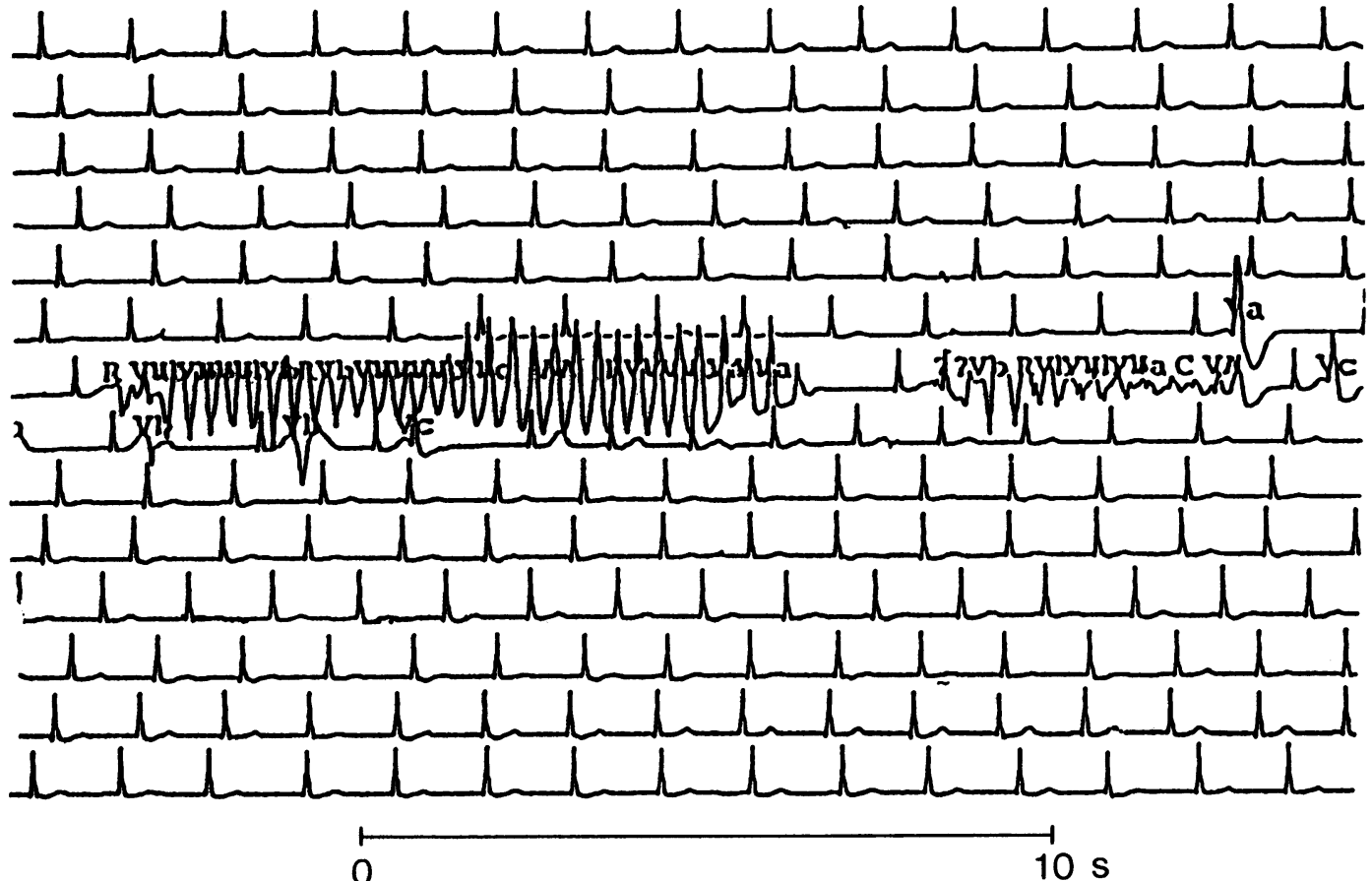

and we wished to treat the adrenergicdependent long QT syndrome with $\beta$ blockade, the patient was given an atrial demand rate-adaptive (AAI-R) system.

Two years later he still had a prolonged QT interval but he had not had any more attacks of syncope. Several Holter recordings did not show any ventricular arrhythmias.

\section{Discussion}

According to Jackman et al the long QT syndrome can be classified into three main groups: pause-dependent long QT syndromes, adrenergic-dependent long $\mathrm{QT}$ syndromes, and an intermediate group with characteristics of both. ${ }^{1}$ The first group is also called acquired long QT syndrome.

The tachycardia associated with the pausedependent long QT syndrome is usually preceded by a long cycle (which enhances the subsequent $U$ wave). After the pause there is a normal QRS complex of sinus origin followed by the first impulse of the torsade de pointes tachycardia. This sequence is in turn preceded by an abnormal impulse, which can either be the last beat of a ventricular tachycardia or a ventricular extra systole. Thus the initiating cycle is short-long-short. ${ }^{2}$

Drugs are the most frequent cause of pause-dependent or acquired long QT syndromes. ${ }^{13}$ Anorexia nervosa, starvation, electrolyte disturbances, and severe bradyarrhythmias are other known causes of pausedependent or acquired long QT syndromes. ${ }^{1}$ Rare cases of classic pause-dependent torsade de pointes without any recognised cause are usually referred to as idiopathic. ${ }^{1}$

The adrenergic-dependent or congenital long QT syndromes are typified by an enhanced adrenergic responsiveness. ${ }^{14}$ The development of episodes of torsade de pointes tachycardia is often associated with an increase in catecholamines. ${ }^{4}$ The congenital long QT syndromes are classified into three syndromes: the Jervell-Lange-Nielsen syndrome, ${ }^{5}$ the Romano-Ward syndrome, ${ }^{67}$ and a nonfamilial form with normal hearing. Episodes of ventricular tachycardias, often torsade de pointes, are more typically seen in children or young adults. The arrhythmias usually appear as a result of physical exercise, pain, fright, sudden startling, or other intense emotional states associated with increased sympathetic activity. Atypical forms of adrenergic-dependent long QT syndromes are seen in patients with intracranial disease, mitral valve prolapse, and after radical neck dissection and carotid endarterectomy. ${ }^{1}$

Patients with classic adrenergic-dependent long QT syndromes show QTU interval prolongations, abnormal TU waves, a lower than normal heart rate and $T$ wave alternans in the electrocardiogram during sinus rhythm, but these abnormalities may vary in size from time to time. These changes may be elicited by manoeuvres that increase sympathetic tone for example, exercise, the cold pressor test, or the Valsalva manoeuvre. ${ }^{89}$

Catecholamine infusion with adrenaline isoprenaline, or phenylephrine has been used to distinguish between the two groups. ${ }^{110} \mathrm{In}$ the pause-dependent long QT syndromes, catecholamine infusion increases the heart rate, shortens the QTU interval, decreases the $U$ wave amplitude, and suppresses ventricular arrhythmias. On the other hand, in the adrenergic-dependent long QT syndromes, catecholamines lengthen the QTU interval and may instigate torsade de pointes tachycardia in susceptible individuals. ${ }^{1}$

It has been suggested that an abnormality of unequal sympathetic tone, with overactivity in the left-sided cardiac efferent nerves accompanied by malfunction of the rightsided cardiac efferents that causes a sympa- 
thetic imbalance and left sympathetic dominance, may cause a disparity in the ventricular recovery process and thus prolong the vulnerable phase. ${ }^{4}$ Another possible cause underlying the adrenergic-dependent long QT syndromes is an intrinsic myocardial abnormality of repolarisation, perhaps an abnormal ion channel protein, that leads to early afterdepolarisations and triggered activity. ${ }^{11} 12$

Yanowitz et al showed that in anaesthetised dogs the QT interval is prolonged after rightsided stellectomy or by left stellate ganglion stimulation. ${ }^{13}$ This accords with clinical observations of accentuation of abnormalities after right stellate block or a reduction in abnormalities by right stellate stimulation and left stellate block. Moss and McDonald first showed that left stellectomy is a highly effective treatment for ventricular arrhythmias in the adrenergic-dependent long QT syndrome and that it significantly reduces mortality. ${ }^{14}$ Otteni et al studied 60 patients undergoing radical neck dissection. ${ }^{15}$ Right radical neck dissection resulted in a large, statistically significant increase in QT interval; the same procedure on the left side of the neck did not alter the QT interval. Ventricular tachycardia of the torsade de pointes type, which caused circulatory arrest, was seen in three patients undergoing right radical neck dissection. Otteni et al suggest that the alteration (surgical trauma) of right sympathetic outflow to the heart by neck dissection probably accounts for QT interval prolongation and the arrhythmias. This is supported by experimental data. ${ }^{13}$ Behne et al studied 40 patients after radical neck dissection. ${ }^{16}$ This study showed significantly more frequent and larger QT prolongation in patients undergoing surgery on the right side of the neck than in those operated on the left side. However, none of the patients experienced any severe arrhythmias. These observations also suggest that sympathetic imbalance with decreased right-sided activity was the pathogenetic mechanism. Pfeiffer et al described a case of intermittent long QT syndrome in a 21 year old woman in whom postmortem examination showed active inflammation of stellate ganglia. ${ }^{17}$

Our patient had no family history of syncopal attacks or long QT syndrome, nor was he taking any drugs known to cause QT prolongation or torsade de pointes tachycardia. Therefore we postulate that the parapharyngeal abscess itself or the surgery on the right side of the neck destroyed, damaged or disturbed conduction in the sympathetic fibres on the right side of the neck, leading to QT prolongation and an adrenergic-dependent long QT syndrome.

The recommended treatment for adrenergic-dependent long QT syndrome with ventricular arrhythmia is $\beta$ blockade. ${ }^{418}$ To protect against bradycardia, which may trigger the onset of torsade de pointes tachycardia during such treatment, our patient was given an atrial demand rate adaptive pacemaker (AAI-R system). ${ }^{19}$

1 Jackman WM, Friday KJ, Anderson JL, Aliot EM, Clark $M$, Lazzara $R$. The long OT syndromes: a critical review, new clinical observations and a unifying hyporeview, new clinical observations and a unity

2 Cranefield PF, Aronson RS. Torsade de pointes and other pause-induced ventricular tachycardias: the short-longhort sequence and early afterdepolarizations. $P A C E$ 1988;11:670-8

3 Stratmann HG, Kennedy HL. Torsade de pointes associated with drugs and toxins: Recognition and management. Am Heart $\mathcal{f}$ 1987;113:1470-82.

4 Schwartz PJ. Idiopathic long QT-syndrome: progress and questions. Am Heart $\mathcal{f}$ 1985;109:399-411.

5 Jervell A, Lange-Nielsen F. Congenital deaf-mutism functional heart disease with prolongation of the Q-T interval and sudden death. Am Heart $\mathcal{F}$ 1957;54:59.

6 Romano C, Gemme G, Pongiglione R. Aritmie cardiache rare dellètà pediatrica. La Clinica Pediatrica 1963;45 656.

7 Ward OC. New familial cardiac syndrome in children. $f$ Ir Med Assoc 1964:54:103.

8 Curtiss EI, Hiebel RH, Shaver JA. Autonomic maneuvers in hereditary Q-T interval prolongation (Romano-Ward syndrome). Am Heart $₹$ 1978;95:420-7.

9 Vincent MG, Jaiswal D, Timothy KW. Effects of exercise on heart rate, QT, QTc and QT/QS2 in the RomanoWard inherited long QT syndrome. Am $₹$ Cardiol 1991; 68:498-503.

10 Wataru S, Tohru O, Takashi K, Katsuro S. Differential response of QTU interval to exercise, isoproterenol, and trial pacing in patients with congenital long QT syndrome PACE 1991;14:1966-70.

11 Zipes DP. The long QT interval syndrome, a rosetta stone for sympathetic related ventricular tachyarrhythmias. Circulation 1991;84:1414-9.

12 Shimizu W, Ohe T, Kurita T, et al. Early afterdepolarisations induced by isoproterenol in patients with congenital long QT syndrome. Circulation 1991;84:1915-23.

13 Yanowitz F, Preston JB, Abildskov JA. Functional Distribution of Right and Left Stellate Innervation to the Ventricles. Circulation Res 1966;18:416-28.

14 Moss AJ, McDonald J. Unilateral cervicothoracic sympathetic ganglionectomy for the treatment of long Q-T interval syndrome. $N$ Engl f Med 1971;285:903.

15 Otteni JC, Pottecher T, Bronner G, Flesch H, Diebolt JR. Prolongation of the Q-T interval and sudden cardiac arrest following right radical neck dissection. Anesthesiology 1983;59:358-61.

16 Behne $M$, Hermann $R$, Lischke $V$, Lörz $M$. Untersuchungen zur Verlängerung der QT-Zeit im EKG nach Operationen am Hals (Neck dissection). HNO 1989:12: 449-53.

17 Pfeiffer D, Fiehring H, Henkel HG, Rostock KJ, Rathgen $\mathrm{K}$. Long QT syndrome associated with inflammatory degeneration of the stellate ganglia. Clin Cardiol 1989; 12:222-4.

18 Crawford MH, Karliner IS, O'Rourke RA, Friedman WF. Prolonged Q-T interval syndrome: successful treatment Prolonged $\mathrm{Q}-\mathrm{T}$ interval syndrome: successful treatment
with combined ventricular pacing and propanolol. Chest with combined

19 Eldar M, Griffin JC, Abbott JA, et al. Permanent cardiac pacing in patients with the long QT syndrome. $\mathcal{F} \mathrm{Am}$ Coll Cardiol 1987;10:600-7. 